\title{
FORCEPS EXTRACTION OF SLIPPERY LENSES IN CASES OF CATARACT*
}

\author{
BY \\ KAILASH NATH \\ M.U. Institute of Ophthalmology and Gandhi Eye Hospital, Aligarh, India
}

IN about one-fifth of all cataracts that come to this hospital for extraction the lens capsule is slippery, so that when one tries to grip it with forceps by the conventional methods, the forceps slip and it is not possible to apply any traction. About 75 per cent. of these cases are Morgagnian cataracts and the rest are intumescent cortical senile cataracts. The technique described below makes it possible to effect a round-pupil upper pole delivery with forceps in these cases with slippery capsules and the method is also useful in cases of senile cataract.

\section{Technique}

Preparation.-The patient is prepared in the routine manner. The important thing in this operation is full dilatation of the pupil. The tension should be neither high nor low, a pre-operative tension of about $20 \mathrm{~mm}$. $\mathrm{Hg}$ (Schiötz) being quite satisfactory. In a hypertensive eye there is danger of vitreous loss, but with low tension the pressure may not be transmitted to the zonule which may not therefore give way according to expectation. For akinesia the author prefers van Lint's technique. One per cent. anethaine is instilled to produce surface anaesthesia, and 2-3 ml. 2 per cent. Procaine is given as a retrobulbar injection followed by bulbar pressure for 2 to 5 minutes.

Operation.-The speculum and superior rectus suture are applied. A 3-mm. limbal flap is fashioned (Fig. 1), a limbal groove is made, and a pre-placed conjunctivo-sclero-corneal suture is prepared.

FIG. 1.-A conjunctivo-sclero-corneal suture and limbal flap are prepared. A keratome section is made and extended with scissors from 3 to 9 o'clock.

With the end of a blunt hook the sclera is gently tapped at 6,5 , and 7 o'clock, thus breaking the corresponding zonule in the lower part of the lens.

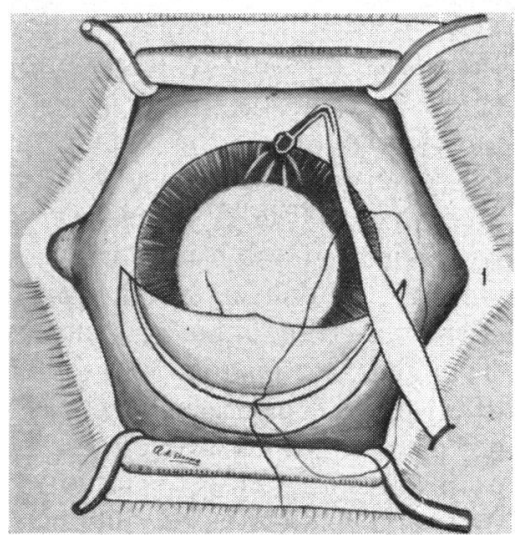

A keratome section is made at 12 o'clock and extended with corneal scissors along the groove. The section is completed from 3 to 9 o'clock in cases of presenile or senile 
intumescent cataract but may be made from 2 to 10 o'clock in cases of Morgagnian cataract, because the lens as a whole is very pliable with a small nucleus, and can be eased out through a section of moderate length. A single or double peripheral button-hole iridectomy is performed.

The next step is to rupture the zonule in the lower part by lightly tapping three to six times with end of a blunt hook at 6 o'clock, and then at 5 and 7 o'clock. One can feel the zonule giving way, and this tapping ensures zonulotomy of the lower two-thirds of the lens.

The scleral lip of the wound is pressed backwards slightly so that the upper edge of the lens moves a little forwards, sliding the lens over the anterior surface of the vitreous. It will be appreciated that the rupture of the lower zonule decreases the general tenseness of the capsule, and that this also makes it less slippery. If the pupil is widely dilated, one can grasp the capsule just anterior to the equator at 12 o'clock with Arruga's forceps, $\dagger$ not with full length of the blades flat on the lens surface but with the tips (Fig. 2). The grasp must not be so hard as to injure the lens capsule but should be so firm that the lens does not slip back. A little pressure on the posterior lip of the section makes it easier to catch hold of the capsule, and if necessary the iris may be retracted by an assistant.

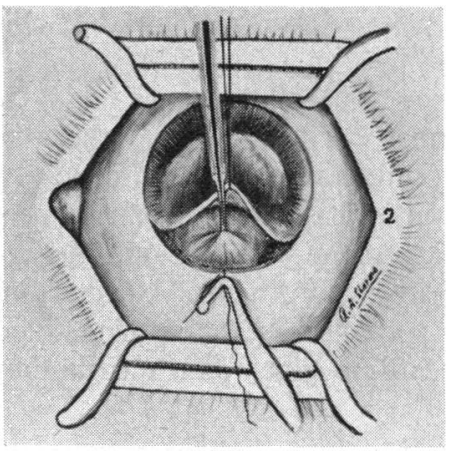

Fig. 2.-The scleral lip is depressed and the capsule is grasped with the very tips of Arruga's forceps. A little co-ordinated traction towards the centre of the cornea and a little pressure below breaks the zonule at 12 o'clock. Complete iridectomy is shown for illustration.

Once the capsule is properly grasped, the procedure for the upper pole delivery is very simple. A little traction by the forceps towards the centre of the cornea, combined with a minimum pressure at the posterior scleral lip of the wound, gives the sensation of tearing a piece of perforated paper. One has to adjust the direction of traction by the forceps and the site of pressure by a spoon or hook according to the part of the zonule one is rupturing (Figs 3 and 4, opposite).

After rupturing the zonule from 10 to 2 o'clock or more, one has only to press the lower part of cornea against the sliding lens which comes out readily breaking its horizontal attachments (Fig. 5, opposite). The upper part of the zonule can also be broken directly with Kirby's hook by varying the direction of traction and lifting the upper edge of the lens.

After the delivery of the lens the pre-placed suture is tied. Two to four post-placed corneo-sclero-conjunctival sutures are used (usually two are sufficient). Pilocarpine drops 2 per cent. are instilled, a bubble of sterile air is injected into the anterior chamber, $1.5 \mathrm{ml}$. of a solution containing 200,000 units penicillin with $0.25 \mathrm{~g}$. streptomycin is injected at 6 o'clock, an antibiotic ointment is applied, and both eyes are bandaged.

In occasional cases of intumescent presenile or senile cataract, the zonule does not give way, and in such cases zonulolysin may be used before the tapping below and the upper pole delivery is effected through a section extending from 3 to 9 o'clock.

† It is rather awkward to use Arruga's forceps, because the angle between the blades and shafts of the forceps should be very small, and it might be easier to manipulate with a straight forceps with very small blunt-ended blades. The idea is to grasp only a small part of the thin capsule with the blunt ends. For lack of manufacturing facilities, the author has been unable to have a forceps made to this design. 


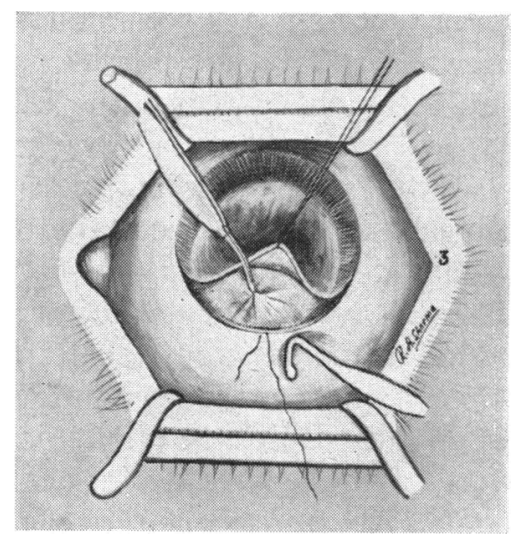

Fig. 3.-Pressure and traction as in Fig. 3 , are exerted at 11 o'clock.

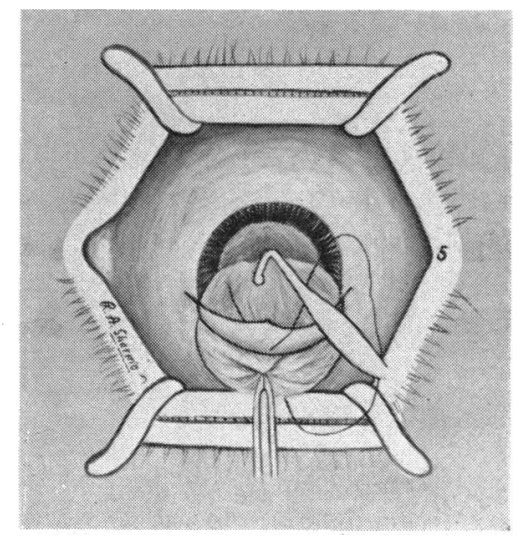

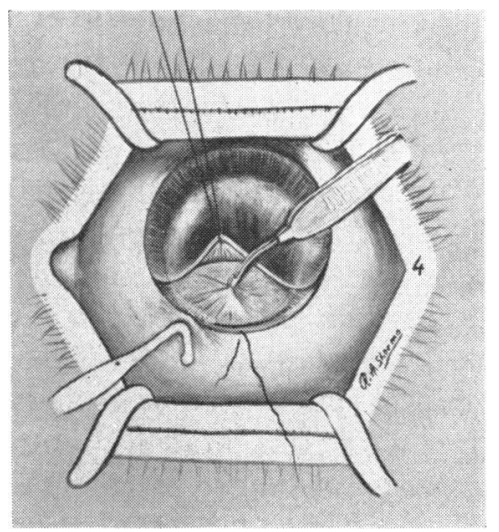

Fig. 4.--Pressure and traction are exerted at 1 o'clock.

FIG. 5.-Traction by the forceps towards 12 o'clock, together with a push from the bottom of the hook, delivers the lens.

\section{Results}

In 63 per cent. of 200 cases with slippery capsules in which this technique was used, the lens was extracted with the capsule intact. In 23 per cent. the capsule ruptured after complete separation of the lower zonule and partial or complete separation of the upper part, so that the extraction though technically extracapsular was practically intracapsular. In the remaining 9 per cent. the capsule ruptured while being grasped at the upper pole; these were all Morgagnian cataracts in which zonulolysin had not been used and the ruptures were due either to incomplete zonular separation at the lower edge or to the fragility of the capsule itself. Excessive pressure or unco-ordinated traction may also rupture the capsule.

\section{Discussion}

Various surgical procedures have been adopted for the extraction of slippery cataracts. Travers (1814) ruptured the capsule with a lancet and then made a small section in the cornea when floating particles were washed away with the aqueous and the remaining cortex was removed with a scoop. According to Kirby (1950), Riddell advocated point puncture of the capsule before extraction in order to collapse it. 
Pellier de Quengsy (Shastid, 1918) performed capsulotomy between puncture and counter-puncture. Weeks (1910) and Elschnig (1925) advocated intracapsular surgery in cases of hypermature and Morgagnian cataracts in which the remaining fragments would be highly toxic. Spaeth (1948) advocated the extra capsular extraction of Morgagnian and intumescent cataracts. Smith's technique of dislocating the lower edge of the lens by pressure, moving it fowards, and then gradually tumbling it upwards, has been much favoured by surgeons doing intracapsular extractions when the capsule is slippery, but this method always carries the danger of vitreous loss. With resistant zonules, the use of zonulolysin before applying Barraquer's suction cup is helpful, the erisophake being applied either at the beginning or when the forceps slip. It is difficult to introduce the cup into a resistant miotic pupil, and there is always a danger of catching the iris, or of the lens being dislocated and vitreous being sucked in. Also, the cup may come away from the lens or the capsule may rupture. On the other hand, Verhoeff's and Kirby's techniques of upper pole delivery (sliding the lens over the anterior surface of the vitreous and leaving a round pupil) are possible only in immature and mature senile cataracts, and Smith's technique in cases of slippery lenses with weak zonules and fragile capsules. Barraquer's suction method is advised in cases with tough zonules and slippery capsules.

The technique described above gives all the advantages of upper pole delivery so that even slippery capsules can be extracted without disturbing the vitreous surface and leaving a round pupil. It is particularly suitable for the intracapsular extraction of Morgagnian cataracts. Intumescent senile or presenile cataracts with tough zonules can also be manipulated with forceps but they behave better after zonulolysis.

\section{Summary}

A technique is described of intracapsular forceps extraction of slippery Morgagnian and intumescent senile cataracts. Upper pole delivery is effected after rupturing the lower zonule. The vitreous is not disturbed and a round pupil remains. The manoeuvres described were performed with Arruga's forceps. A suitable new instrument is desirable but has yet to be perfected.

I owe my thanks to Mr. R. A. Sharma, the medical artist, and Mr. U. C. Gupta, the photographer, of the Muslim University Institute of Ophthalmology.

\section{REFERENCES}

ELSCHNiG, A. (1925). Amer. J. Ophthal., 8, 355.

KIRBY, D. B. (1950). "Surgery of Cataract", pp. 29, 30, 332, 358. Lippincott, Philadelphia.

RIDDELL, W. Cited by Kirby (1950), p. 405.

SHASTID, T. H. (1918). Article on G. Pellier de Quengsy (1750-1835) in "The American Encyclopaedia and Dictionary of Ophthalmology", ed. C. A. Wood, vol 12, p. 9403. Cleveland Press, Chicago. (Cited by Kirby, 1950, p. 29).

Spaeth, E. B. (1948). "Principles and Practice of Ophthalmic Surgery", 4th ed. p. 606. Lea and Febiger, Philadelphia.

Travers, B. (1814). " A Synopsis of Diseases of the Eye and their Treatment", 2nd ed. 1821. Longmans, London. (Cited by Kirby, 1950, p. 30).

WeEks, J. E. (1910). "A Treatise on Diseases of the Eye", p. 851. Philadelphia. 